\title{
Neuropsychomotor development and genomic stability associated to folate and blood iron levels in preschool children
}

\author{
Maiara de Queiroz Fischer 1 \\ Patrícia Molz 2 \\ Liziane Hermes 3 \\ Caroline dos Santos 4 \\ Luana Beatriz Limberger 5 \\ Diene da Silva Schlickmann 6 \\ Jorge André Horta 7 \\ Jane Dagmar Pollo Renner 8 \\ Daniel Prá 9 \\ Silvia Isabel Rech Franke 10 \\ 1,4,5,6,9 Laboratório de Nutrição Experimental. Universidade de Santa Cruz do Sul. Santa Cruz do Sul, RS, Brasil. \\ 2 Programa de Pós-graduação em Medicina e Ciências da Saúde. Faculdade de Medicina. Pontifícia Universidade Católica do Rio Grande do Sul. Av. Ipiranga, 6681. Porto \\ Alegre, RS, Brasil. CEP: 90.619-900.E-mail: patricia.molz@gmail.com \\ 3,7,8,10 Programa de Pós-graduação em Promoção da Saúde. Universidade de Santa Cruz do Sul. Santa Cruz do Sul, RS, Brasil.
}

\begin{abstract}
Objectives: to evaluate the neuropsychomotor development and the genomic stability associated to folate and blood iron levels in preschool children.

Methods: a cross-sectional study in which evaluated the biochemical exams (complete hemogram, serum ferritin, iron and folate), neuropsychomotor development (Denver II Test) and genotoxicity (micronuclei cytome in buccal mucosa cells) of 55 children aging 36-59 months old. Student's T test, Kruskal-Wallis and Pearson's or Spearman's correlation tests were applied with a significance level of $p<0.05$ for data analysis.

Results: the prevalence of anemia was $1.8 \%$. The Denver II test classified $32.7 \%$ of the children as normal and $67.3 \%$ were suspected of having a delay. The children suspected of having a delay presented a slight reduction on hemoglobin and hematocrit ( $p=0.05$ and $p=0.14)$, intermediate reduction on iron and folate ( $p=0.29$ and $p=0.23)$ and a notable reduction on ferritin $(p=0.03)$. Folate and iron were significantly associated to the frequency of cells with DNA damages $(p<0.05)$. The frequency of binucleated cells was positively associated to the Red Cell Distribution Width $(R D W)(r=0.56 ; p=0.02)$ in children without a delay and negatively with folate ( $r=-0.334 ; p=0.047)$ in children with a delay.

Conclusions: this study showed a low prevalence of anemia, but a high rate of children suspected of having a neuropsychomotor, possibly associated to low ferritin levels. Additionally, iron and folate were associated to DNA damage which may have contributed to the psychomotor development delay.
\end{abstract}

Key words Iron, Folate, Child, Neuropsychomotor development, Genomic stabilitya 


\section{Introduction}

Considering essential nutrients, iron and folate play a primordial role in the human metabolism, and are fundamental to produce energy and cellular metabolism. The deficiency of both nutrients represents a worldwide public health problem affecting all age groups, especially pregnant women and preschool children. ${ }^{1,2}$

Evidence suggests that iron deficiency provokes long term effects, such deficiencies as cognitive and psychomotor development, as well as reduction on the productive capacity. Also, the child's psychological state and eating behavior are related to many nutritional aspects in this phase. ${ }^{3-5}$

Folate plays a key role at the normal cell division and during growth and development periods. The causes of folate deficiency range from an inadequate eating habit to conditions associated to the increase of cellular renewal. Furthermore, its deficiency can affect the memory and the language capacity, as well as the onset of megaloblastic anemia. 1,5,6

The child development is the interaction result between genetic, biologic and environmental factors. Thus, the "The Denver Developmental Screening Test (Denver II)" is a child development risk tracking test, which estimates the development level capable of investigating the early possible alterations in the children's psychomotor development between $0-6$ years old. 7,8

Iron and folate also act in important cellular processes for the nerve cells and for being considered essential for the DNA synthesis and repair.9,10 These nutrients can act in the genome stability playing an important role in the DNA metabolism. Iron is required for the transportation of oxygen, as well as folate, which the deficiency is related to the micronuclei formation of a specific DNA damage type. 2,11

In this sense, there are different types of tests in the medical literature which assess the genome stability. The micronuclei cytome in buccal mucosa cells assay (BMCyt) is a cytogenetic technique used to measure biomarkers of DNA damage (originated from a defect during cellular division), as well as the cellular death in the oral epithelium in a quick and noninvasive manner. 12

Therefore, the objective of this study was to evaluate the neuropsychomotor development and the genomic stability associated to the folate and blood iron levels in preschool children.

\section{Methods}

This is a cross-sectional study with children between 36 and 59 months old, both sexes, enrolled in the children's school in Venâncio Aires city in, Rio Grande do Sul State, Brazil. Children's parents/guardians that have participated in the previous study (105 children) were invited to participate in this present study, which was approved by the Research Ethics Committee at the Universidade de Santa Cruz do Sul - UNISC (CAAE 39631014.3.0000.5343, document number: 928.529). 50 children were excluded from the study because they had moved and were not able to be located or found. All the stages were performed after the child's parents/guardian had signed the Informed Consent Form.

Through the questionnaire applied for the parent/guardian, the information regarding the child was collected, such as: date of birth, information about the use of supplementation and the socioeconomic data, the latter one is classified according to the Brazilian Association of Research Companies (Associação Brasileira de Empresas de Pesquisa ABEP). ${ }^{13}$ Afterwards, each child was conducted to a specific room in their own schools, in order to perform the anthropometrics assess and collect oral mucosa cells and also to identify risks of neuropsychomotor development.

The anthropometric measurements (weight and height) were collected according to the Technical Norms System on Eating and Nutritional Surveillance (Norma Técnica do Sistema de Vigilância Alimentar e Nutricional - SISVAN), 14 using a digital weighing scale $\left(\right.$ Plenna $\left.{ }^{\circledR}\right)$ and a vertical portable stadiometer (Invicta Plastics ${ }^{\circledR}$ ). From these anthropometric measurements, the body mass index (BMI) was calculated, the classified nutritional state was according to the World Health Organization (WHO), 14 the BMI age (BMI/A) and the $\mathrm{z}$-score. The data were organized and assessed in Anthro, program from WHO.

The DNA damage level was assessed by the BMCyt test. First, the oral mucosa cells were collected located in the internal region of the cheeks with the support of the cytobrush, this material is stored in falcons containing $1 \mathrm{~mL}$ of methanol. Then, the samples were sent to the Laboratory of Experimental Nutrition (Laboratório de Nutrição Experimental) at the Universidade de Santa Cruz do Sul (UNISC) where the slides were prepared, stained and analyzed according to Thomas et al.protocol.12

The neuropsychomotor development was assessed by using The Denver Developmental 
Screening Test (Denver II), 7,8 in which it is possible to investigate four areas of the development: personal-social, fine motor, language and gross motor, composed by 125 items/activities in total. The test allows to verify the capacity to understand instructions, the conceptual of the word, figure nomination and personal-social abilities, which supports the choice of this test in this study for its high sensibility.

The time to perform the test was approximately twenty minutes, in which the items applied were for ages between 36 and 59 months old. At the moment of applying the test, each of the items was registered as "approved" or "failed" on the specific sheet form

In the evaluation on each of the items tested the scores were assigned to allow the interpretation of the tested items in the following: "normal", when the child executed all of the items/activities expected for his/hers age; "caution", when the child did not execute or refused to execute the activity that was done by 75 to $90 \%$ of the children respective to his/her age; and "delay", when the child did not execute an activity done by over $90 \%$ of the children. According to the evaluation, the Denver II allows two global classifications: Normal, when there is no delays or, the most, one single caution; and Suspect of delay, when there is two or more cautions and/or one or more delays. ${ }^{7}$

In the second stage of the study, a blood collection was performed by trained professional from a clinical analysis laboratory in Venâncio Aires city in RS. $5.0 \mathrm{~mL}$ of blood were collected from each child and stored in different flasks, accordingly identified and labeled, and sent to the Laboratory of Biochemistry Exercise (Laboratório de Bioquímica do Exercício) - UNISC where the complete hemogram (hemoglobin, hematocrit, mean corpuscular volume - MCV, mean corpuscular hemoglobin - $\mathrm{MCH}$, mean corpuscular hemoglobin concentration - MCHC and Red Distribution Width - RDW), was performed by using the analyser Sysmex, XS-800i, for ferritin serum and to determine the iron, Miura 200 (I.S.E. S.r.l. Clinical Chemistry Solution, Italy) equipment was used by the turbidimetry and calorimetry methods, respectively. Moreover, the folate serum levels were determined by the immunochemiluminescence method by using the ARCHITECTImmunoassay Analyzer (Abbott Diagnostics, USA) equipment in a clinical analysis laboratory in Santa Cruz do Sul city in, RS. The Reactive C Protein (PCR) levels were evaluated as an inflammatory marker $(\mathrm{PCR}<0.6 \mathrm{mg} / \mathrm{dL})$, once that in case the individual presented infections, the ferritin results could be altered. The reference values used for the biochemical analysis were: $>11.0 \mathrm{~g} / \mathrm{dL}$ for hemoglobin, $>33 \%$ for hematocrit, $>79 \mathrm{fL}$ for $\mathrm{MCV},>27.4 \mathrm{pg}$ for $\mathrm{MCH},>34.4 \mathrm{~g} / \mathrm{L}$ for $\mathrm{MCHC}$, $>11.5 \%$ for RDW, $>12 \mathrm{ng} / \mathrm{mL}$ for ferritin, $>50 \mu \mathrm{g} / \mathrm{dL}$ for iron and $>3.10 \mathrm{ng} / \mathrm{mL}$ for folate.

The statistical analyzes were performed in the Statistical Package for Social Sciences (SPSS) version 20.0 software and the graphs were built in the GraphPad Prism version 6.01 software. The hematological data were analyzed by the Student's $t$ test and the DNA damage by Kruskal-Wallis nonparametric test. The Pearson's or Spearman's correlation analyzes were also used. The significance level was $p<0.05$.

\section{Results}

Among the 105 children from the previous study, 50 children were excluded due to their refusal to participate in the research, change of address or the parents/guardians were not interested/available in order to take the children to the laboratory and other reasons that may have compromised their participation. Therefore 55 children participated in this study with the average age of $49.03 \pm 6.19$ months old, $54.5 \%$ were females, $45.5 \%$ were enrolled in level III (children from 36 to 47 months old) and $54.6 \%$ in level pre A (children above 48 months old).

Most of the evaluated children in this present study, were eutrophic $(67.3 \%)$, about half of them belonged to B2 socioeconomic class and $76.4 \%$ of these children were supplemented with iron from 6 to 24 months old (Table 1).

In this present study, the prevalence of anemia was $1.8 \%$, hemoglobin was only considered. Evaluating the ferritin serum and iron levels, 3.6\% and $10.9 \%$ of the children were observed respectively, presenting values below the recommendation and no child presented folate deficiency.

According to the Denver II test, $32.7 \%$ of the children were classified as normal and $67.3 \%$ suspected of neuropsychomotor developmental delay.

Associating the hematologic variables with the Denver II test, it was verified that the children suspected of neuropsychomotor developmental delay presented a slight reduction (less than $2 \%$ ) in the hematocrit and hemoglobin levels ( $p=0.15$ and $p=0.05$, respectively), in the intermediate decrease on iron $(5 \%, p=0.29)$ and folate $(8 \%, p=0.23)$ levels and a notable reduction in the ferritin levels $(17 \%$, $p=0.03)$. The children considered as normal 
presented a reduced mean of corpuscular hemoglobin $(\mathrm{MCH})$, a mean concentration of corpuscular hemoglobin (MCHC) and iron However, there were high frequency of binucleated cells, micronuclei, bud and bridge, but no significant statistical difference ( $p>0.05$; Table 2$)$.

Evaluating the association between the hematological parameters with the DNA damage, it was verified that there is a negative correlation between the serum iron levels with the micronucleus frequency ( $\mathrm{r}=0.27$ and $p=0.05)$ and the frequency of nuclear bridges cells ( $\mathrm{r}=0.28$ and $p=0.04$; Figure 1$)$. The folate level in the blood presented a negative correlation with the frequency of the binucleated cells ( $\mathrm{r}=0.28$ and $p=0.04)$ and a positive correlation with the nuclear bud cells $(\mathrm{r}=0.32$ and $p=0.02$; Figure 1).

According to the Denver II classification criteria, when the hematological parameters were associated to the DNA damage, it was verified a positive correlation between the red distribution width (RDW) levels and the binucleated cells frequency $(\mathrm{r}=0.55 ; p=0.02)$ among the children without the neuropsychomotor developmental delay. In relation to the children with delay, it was observed a negative correlation between the folate levels in the blood and the binucleated cells frequency $(\mathrm{r}=0.33 ; p=0.05)$.

Table 1

Samples of preschool children characteristics.

\begin{tabular}{|c|c|c|c|}
\hline Variables & $\mathbf{N}$ & $\%$ & $\bar{x} \pm S D$ \\
\hline Children's age (years) & & & $49.03 \pm 6.19$ \\
\hline \multicolumn{4}{|l|}{ Sex } \\
\hline Male & 25 & 45.5 & \\
\hline Female & 30 & 54.5 & \\
\hline \multicolumn{4}{|l|}{ Nutritional State } \\
\hline Underweight & 1 & 1.8 & \\
\hline Eutrophy & 37 & 67.3 & \\
\hline Overweight & 16 & 29.1 & \\
\hline Obesity & 1 & 1.8 & \\
\hline \multicolumn{4}{|l|}{ Social Class } \\
\hline B1 & 9 & 16.4 & \\
\hline B2 & 28 & 50.9 & \\
\hline $\mathrm{C} 1$ & 15 & 27.3 & \\
\hline $\mathrm{C} 2$ & 3 & 5.4 & \\
\hline \multicolumn{4}{|l|}{ Supplementation } \\
\hline Yes & 42 & 76.4 & \\
\hline No & 13 & 23.6 & \\
\hline
\end{tabular}

$\mathrm{SD}=$ standard deviation. 
Table 2

Comparison between the means of the parameters according to Denver II classification.

\begin{tabular}{lccc}
\hline & $\begin{array}{c}\text { Normal } \\
(\mathbf{n}=\mathbf{1 8})\end{array}$ & $\begin{array}{c}\text { Suspected of neuropsychomotor } \\
\text { developmental delays }(\mathrm{n}=37)\end{array}$ & $p$ \\
\cline { 2 - 3 } & $\overline{\mathrm{X}} \pm \mathrm{SD}$ & $\overline{\mathrm{X}} \pm \mathrm{SD}$ & \\
\hline Hemoglobin (g/dL) & $12.66 \pm 0.76$ & $12.44 \pm 0.63$ & 0.14 \\
Hematocrit (\%) & $36.90 \pm 1.99$ & $36.05 \pm 1.71$ & 0.05 \\
MCV (fL) & $78.89 \pm 5.67$ & $78.70 \pm 2.84$ & 0.43 \\
MCH (pg) & $27.09 \pm 2.39$ & $27.16 \pm 1.24$ & 0.44 \\
MCHC (g/L) & $34.29 \pm 0.97$ & $34.51 \pm 0.93$ & 0.21 \\
RDW (\%) & $13.09 \pm 1.68$ & $12.99 \pm 0.76$ & 0.41 \\
Ferritin (ng/mL) & $49.74 \pm 13.68$ & $41.49 \pm 16.08$ & 0.03 \\
Iron ( $\mu \mathrm{g} / \mathrm{dL})$ & $78.80 \pm 27.91$ & $82.89 \pm 24.16$ & 0.29 \\
Folate (ng/mL) & $11.77 \pm 4.61$ & $10.82 \pm 4.27$ & 0.23 \\
CRP (mg/dL) & $0.32 \pm 0.34$ & $0.31 \pm 0.45$ & 0.75 \\
Binucleated(number of cells) & $2.06 \pm 1.51$ & $1.86 \pm 1.90$ & 0.44 \\
Micronuclei (number of cells) & $1.50 \pm 1.79$ & $0.86 \pm 1.08$ & 0.22 \\
Bud (number of cells) & $0.94 \pm 1.30$ & $0.76 \pm 0.86$ & 0.96 \\
Bridge (number of cells) & $0.89 \pm 0.96$ & $0.46 \pm 0.69$ & 0.10
\end{tabular}

SD = standard deviation; $p$ : level of significance according to the two-tailed Mann-Whitney U test (DNA damage and CRP) and one side Student's $t$ test (hematological parameters). MCV = Mean Corpuscular Volume; MCH = Medium Corpuscular Hemoglobin; MCHC = Mean Corpuscular Hemoglobin Concentration; RDW = Red Distribution Width; CRP=C-Reactive Protein (only 35 individuals).

Figure 1

Correlation between serum iron levels and micronuclei (A), iron and nuclear bridges (B), folate and binucleated cells (C) and folate and nuclear buds (D) in children $(n=55)$ aged between 36-59 months . $r$ and $p$ : correlation coefficient and significance level, respectively, according to the Pearson's test indicated in this figure.
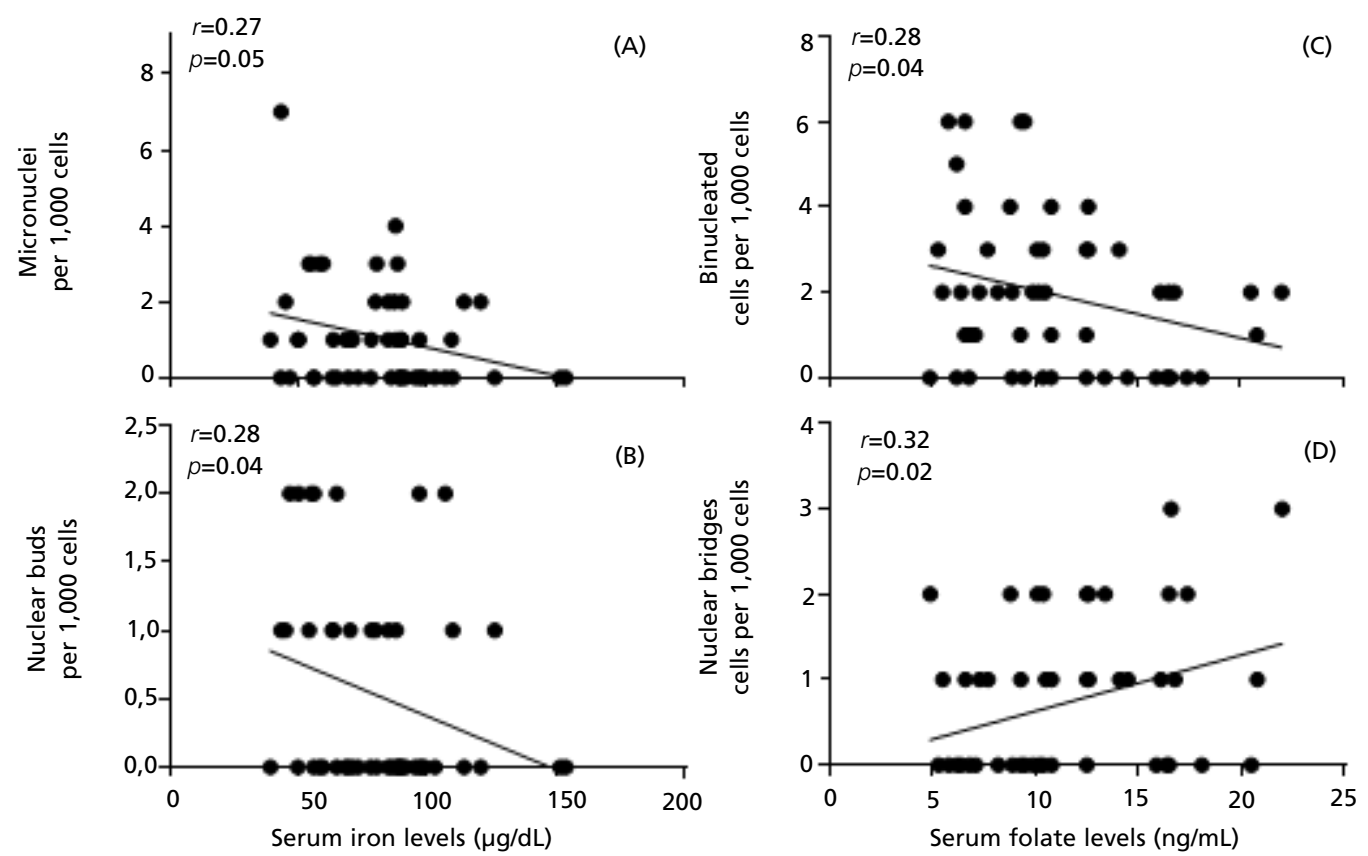


\section{Discussion}

The prevalence of anemia found in this present study is considered normal, according to the classification of importance level as a public health problem, defined by the World Health Organization (WHO), 5 which classifies as normal, the prevalence of anemia $\leq 4.9 \%$. Prá et al. 15 while conducting a research in Santa Cruz do Sul city in RS, which also belongs to the Vale of Taquari and Rio Pardo regions, evaluated 30 healthy children with an average age of $11.5 \pm 2.5$ years old and observed a prevalence of anemia similar to the one found in our study (3.3\%, only one individual with anemia). In a meta-analysis, assessing the prevalence of anemia in children from different Brazilian regions, a variation of the prevalence of anemia was verified superior to the one found in this present study, between $35.0 \%$ and $68.8 \%, 16$ indicating a moderate-severe Brazilian public health problem.

The low prevalence of anemia rate and adequate levels of folate found in this present study may be justified by the fact that these children had already participated in previous researches (conducted in 2012 and 2013), because the parents/guardians had already been oriented about the bioavailability and foods sources of iron.

Regarding the ferritin serum and iron levels, these were found in this present study, $3.6 \%$ and $10.9 \%$ below the recommended values, respectively. These iron deficiency percentages $(10.9 \%)$ were inferior to those found in another study conducted in the South of Brazil, which found $16.1 \%$ of the children between 3 and 4 years old iron deficient according to the ferritin results. 17

It is important to emphasize that the ferritin results may be altered, when comparing to the serum iron in situations of inflammation. Therefore, it is recommended to evaluate the PCR as an inflammatory marker. Among the children that participated in the study, it was possible to evaluate the PCR levels in only $66.6 \%$ which $80.0 \%$ had the recommended values, however $20 \%$ of the sample presented some alteration in the PCR levels. This aspect must be taken in consideration as a limitation of this study. It is suggested that the low levels of anemia and iron deficiency, as well as the adequate levels of folate found in our study may be due to the socioeconomic classification of the household (50.9\% middle class) and adequate nutritional state ( $67.3 \%$ of eutrophy) to most of the individuals. 5

Our results also indicated a high prevalence of iron supplementation in children at 6 and 24 months old $(76.4 \%)$, differently from the data found in
Oliveira et al.18 study which verified a low prevalence of supplementation usage in Porto Velho city in Acre, Brazil (13.5\%). It also needs to be taken in consideration about the region's cuisine which presents a high bread and pasta consumption which are produced with wheat and corn flour, enriched with iron $(4.2 \mathrm{mg} / 100 \mathrm{~g}$ of flour) and folic acid (150 $\mu \mathrm{g} / 100 \mathrm{~g}$ of flour), according to a specific legislation since 2004 in Brazil. 19,20 The Taquari and Rio Pardo regions also present a high meat ingestion, thus, the iron (heme iron) contained in this type of food is better absorbed when compared to the non-heme iron. 5,21 Another factor that must be taken in to consideration is the consumption of food with vitamin C sources which could facilitate the absorption of non-heme iron. Previous researches indicate that this region presents a high consumption of meat and bowels sources of vitamin $\mathrm{C}$, such as the mandarin (tangerine). 15

Our findings reveal that $67.3 \%$ of the evaluated children by the Denver II test had a performance with a suspicion on neuropsychomotor developmental delay, a value above of the one found in Brito et al.,8 which evaluating children between 4 and 5 years old found that $46.3 \%$ had neuropsychomotor developmental delay.

In relation to the hematological variables associated to the Denver II test, lower hemoglobin levels were found, hematocrit, MCV, RDW, PCR, ferritin and folate in children suspected of neuropsychomotor development delay, corroborating with Schatz et al.22 study. The authors assessed the effectiveness of the Denver II test with 50 children with sickle cell anemia between 1 and 3.5 years old and observed that $30 \%$ of them were suspected of neuropsychomotor development delay besides presenting lower hematocrit levels when compared to normal children.

Some limitations of the Denver II test could be associated with the elevated number of children suspected of neuropsychomotor developmental delay according to monitors' reports may be due to the facts that the children got very tired and sleepy in the following day, they slept the night before at hours that are considered late; shyness; lack of empathy with the interviewer; lack of incentive at home by their parents who may not have had the patience to teach and play with their children, in many cases, some activities of the Denver II test are complex and are not adapted to the current days, and that the Denver II test does not allow to stimulate the child to practice the activities during the test in order to not interfere with the neutrality in the development of the activity by the child. 
Fenech ${ }^{23}$ demonstrated that both the micronutrients deficiency with the excess may jeopardized the effects on genomic damages. In our study, a high frequency of micronucleus, binucleated cells, nuclear bud and bridge on normal children was observed. We did not find in the literature an explanation for such finding. However, our group hypothesizes that the probable cause of these damages are a high cellular proliferation due to the intense formation of immunologic memory in the lymphocytes $\mathrm{T}$ at this age and, because of that, it presents a high propensity of DNA damage once that the lymphocytes suffer DNA breaks at the somatic recombination. 24,25 Future studies are necessary to test and confirm this hypothesis.

The shortage of folate is known to cause chromosomal amplification damage which probably may contribute to the micronuclei formation, nuclear buds and bridges. Prá et al. 15 verified that the iron ingestion decreased the frequency of micronucleus and nuclear bridges.

The BMCyt is an effective technique for the study on organic cellular and nuclear deficiency caused both by the deficiency and by the excess of micronutrients. 26 Moreover, it is known that the neuropsychomotor development on children should be stimulated by the parents/guardians in the initial learning phase what would contribute to decrease neuropsychomotor delays. Our results showed that the iron levels reduced the frequency of micronucleus and nuclear bridges, while the folate reduced the binucleated cells and, however, increased the frequency of nuclear buds. The high number of children suspected of neuropsychomotor developmental delay by the Denver II test in this present study is concerned suggesting that these children should be evaluated again in the future.
Another relevant aspect is the expressive result of the DNA damage, which shows a strong influence of the micronutrients researched.

The red distribution width (RDW), which is used at the evaluation of the size variability of the erythrocytes could be increased at the megaloblastic anemia, which, on the other hand, may be caused by the folate deficiency.5,6 In our results were observed that the normal children presented higher levels of red distribution width (RDW), associating more frequently to the binucleated cells. However, with these same children, it was observed that the folate in the blood had decreased the frequency of binucleated cells. More studies are necessary to explore the effect between these levels, especially the red distribution width (RDW) and folate on the neuropsychomotor development.

A limitation in this study was that the non inclusion of the food consumption that could have been relevant information about the quantity and quality of the children's diet. Also, we should consider the losses generated at the blood collecting moment because many of the parents/guardians did not have interest or availability to take the children to the location.

We can conclude that this present research showed that in relation to the studied population there was a low prevalence rate of anemia and adequate levels of folate. However, it was verified the existence of a high rate of children suspected of neuropsychomotor developmental delay. An association between the nutrients levels (blood iron and folate) and DNA damage was also observed. Additional studies are necessary to evaluate the role of these micronutrients in the genotoxicity and neuropsychomotor development in children.

\section{References}

1. Algarin C, Karunakaran KD, Reyes S, Morales C, Lozoff B, Peirano P, Biswal B. Differences on Brain Connectivity in Adulthood Are Present in Subjects with Iron Deficiency Anemia in Infancy. Front Aging Neurosci. 2017; 9: 54.

2. Casey GJ, Tinh TT, Tien NT, Hanieh S, Cavalli-Sforza LT, Montresor A, Biggs BA. Sustained effectiveness of weekly iron-folic acid supplementation and regular deworming over 6 years in women in rural Vietnam. PLoS Negl Trop Dis. 2017; 11 (4): e0005446.

3. Yılmaz D, Bayar-Muluk N, Bayoğlu B, İdil A, Anlar B. Screening 5 and 6 year-old children starting primary schoo for development and language. Turk J Pediatr. 2016; 58 (2): $136-44$

4. grawal S, Berggren KL, Marks E, Fox JH. Impact of high iron intake on cognition and neurodegeneration in humans and in animal models: a systematic review. Nutr Rev. 2017; 75 (6): 456-70

5. WHO (World Health Organization). Iron deficiency anemia: assessment, prevention and control. Geneva: World Health Organization; 2001.

6. Zeeshan F, Attia Bari SF, Jabeen U, Rathore AW. Correlation between maternal and childhood VitB12, folic acid and ferritin levels. Pak J Med Sci. 2017; 33 (1): 162-6.

7. Frankenburg WK, Dodds J, Archer P, Bresnick B, Maschka P, Edelman N,Shapiro H. Denver II Training Manual. Denver: Denver Developmental Materials; 1992. 
8. Brito CML, Vieira GO, Costa COM, Oliveira NF Desenvolvimento neuropsicomotor: o teste de Denver na triagem dos atrasos cognitivos e neuromotores de pré-escolares. Cad Saúde Pública 2011: 27 (7): 1403-14.

9. Bailey LB, Stover PJ, McNulty H, Fenech MF, Gregory JF, Mills JL, Pfeiffer CM, Fazili Z, Zhang M, Ueland PM, Molloy AM, Caudill MA, Shane B, Berry RJ, Bailey RL, Hausman DB, Raghavan R, Raiten DJ. Biomarkers of Nutrition for Development-Folate Review. J Nutr. 2015; 145 (7): 1636S-80S.

10. Abdullah K, Thorpe KE, Mamak E, Maguire JL, Birken CS, Fehlings D, Hanley AJ, Macarthur C, Zlotkin SH, Parkin PC. Optimizing early child development for young children with non-anemic iron deficiency in the primary care practice setting (OptEC): study protocol for a randomized controlled trial. Trials. 2015; 16 (1): 132.

11. Prá D, Franke SIR, Henriques JAP, Fenech M. Review: Iron and Genome Stability: an update. Mutat Res. 2012: 733 (1); 92-9.

12. Thomas P, Harvey S, Gruner T, Fenech M. The buccal cytome and micronucleus frequency is substantially altered in Down's syndrome and normal ageing compared to young healthy controls. Mutat Res. 2008; 638 (1): 37-47.

13. ABEP (Associação Brasileira de Empresas de Pesquisa). 2013. [acesso em 1 mar 2015]. Disponível em www.abep.org/new/criterioBrasil.aspx.

14. Brasil. Ministério da Saúde. Secretaria de Atenção à Saúde. Departamento de Atenção Básica. Orientações para a coleta e análise de dados antropométricos em serviços de saúde. Brasília, DF; 2011

15. Prá D, Bortoluzzi A, Müller LL, Hermes L Horta JA, Maluf SW, Henriques JA, Fenech M, Franke SI. Iron intake, red cell indicators of iron status, and DNA damage in young subjects. Nutrition. 2011; 27 (3): 293-7.

16. Vieira RCS, Ferreira GS. Prevalência de anemia em crianças brasileiras, segundo diferentes cenários epidemiológicos. Rev Nutr. 2010; 23 (3): 433-44.

17. Bortolini GA, Vitolo MR. Relação entre deficiência de ferro e anemia em crianças de até 4 anos de idade. J Pediatr. 2010; 86 (6) 488-92.
18. Oliveira CSM, Augusto RA, Muniz PT, Silva AS, Cardoso MA. Anemia e deficiência de micronutrientes em lactentes atendidos em unidades básicas de saúde em Rio Branco, Acre, Brasil. Ciênc Saude Colet. 2016; 21 (2): 517-30.

19. Brasil. Misterio da Saúde. Resolução RDC n 344, de 13 de dezembro de 2002. Aprova regulamento técnico para a fortificação das farinhas de trigo e das farinhas de milho com ferro e ácido fólico. Diário Oficial da União, Brasília, DF; 2002.

20. Steluti J, Selhub J, Paul L, Reginaldo C, Fisberg RM, Marchioni DML. An overview of folate status in a population-based study from São Paulo, Brazil and the potential impact of 10 years of national folic acid fortification policy. Eur J Clin Nutr. 2017. doi: 10.1038/ejen.2017.60.

21. Bortolini GA, Vitolo MR. Importância das práticas alimentares no primeiro ano de vida na prevenção da deficiência de ferro. Rev Nutr. 2010; 23 (6): 1051-62.

22. Schatz J, McClellan CB, Puffer ES, Johnson K, Roberts KW. Neurodevelopmental screening in toddlers and early preschoolers with sickle cell disease. J Child Neurol. 2008; 23 (1): 44-50.

23. Fenech M. Dietary reference values of individual micronutrients and nutriomes for genome damage prevention current status and a road map to the future. Am J Clin Nutr. 2010; 91 (5):1438-54

24. $\mathrm{Xu}$ Y. DNA damage: a trigger of innate immunity but a requirement for adaptive immune homeostasis. Nat Rev Immunol. 2006; 6 (4): 261-70.

25. Dadi S, Le Noir S, Asnafi V, Beldjord K, Macintyre EA. Normal and pathological V(D)J recombination: contribution to the understanding of human lymphoid malignancies. Adv Exp Med Biol. 2009; 650: 180-94.

26. Wang XU, Thomas P, Xue J, Fenech M. Folate deficiency induces aneuploidy in human lymphocytes in vitroevidence using cytokinesis-blocked cells and probes specific for chromosomes 17 and 21. Mutat Res. 2004; 551 (1): $167-80$

Received on November 8, 2016

Final version presented on June 27, 2017

Approved on July 10, 2017 